Bull. Mater. Sci., Vol. 36, No. 4, August 2013, pp. 553-558. (C) Indian Academy of Sciences.

\title{
Characterization of molybdenum-doped indium oxide thin films by spray pyrolysis technique
}

\author{
S M ROZATI* and Z BARGEBIDI \\ Department of Physics, University of Guilan, Rasht 41335, Iran
}

MS received 4 November 2010; revised 25 August 2011

\begin{abstract}
In this research, indium oxide nanostructure undoped and doped with Mo were prepared on glass substrates using spray pyrolysis technique. Various parameters such as dopant concentration and deposition temperatures were studied. Structural properties of these films were investigated by X-ray diffraction and scanning electron microscopy. Electrical and optical properties have been studied by Hall effect and UV-Visible spectrophotometer, respectively. The thickness of the films was determined by PUMA software. The variation of refractive index, extension coefficient and bandgap of these films also were investigated.
\end{abstract}

Keywords. Molybdenum-doped indium oxide; spray pyrolysis; thin films.

\section{Introduction}

Transparent conducting oxide (TCOs) films such as $\operatorname{In}_{2} \mathrm{O}_{3}$, $\mathrm{ZnO}, \mathrm{SnO}_{2}$ and $\mathrm{In}_{2} \mathrm{O}_{3}: \mathrm{Sn}$ (ITO), $\mathrm{In}_{2} \mathrm{O}_{3}$ :Mo (IMO), etc due to their high optical transparency in the visible region and good electrical conductivity are important (El Hichou et al 2004). There are many applications of using TCOs like in solar cell devices (Anna Selvan et al 2006), liquid crystal displays (Ryu et al 2003), wave guide electron devices (Lessman and Hummelgen 2004), light emitting diode (Chen et al 2003; Macedo et al 2008) and gas sensors (Korotcenkov et al 2004). In this study, one of the important process parameters in TCO films is the study on effect of doping mechanism (Rozati and Akesteh 2007, 2008; Rozati et al 2009). A large variety of techniques have been developed for transparent conducting oxides deposition viz., chemical vapour deposition (Brown et al 2000), sputtering (Boycheva et al 2007), spray pyrolysis (Golshahi et al 2009), sol-gel (Tahar et al 1997) and pulsed laser ablation (Kim et al 2006). $\mathrm{In}_{2} \mathrm{O}_{3}$ transparent conducting thin films are $n$-type semiconductors with a wide energy bandgap of $3 \cdot 6 \mathrm{eV}$. The structure of $\mathrm{In}_{2} \mathrm{O}_{3}$ in its crystalline form is body centred cubic with a lattice constant of 10.118 $\AA$ (Korotcenkov et al 2005). Since a few studies have been carried out on IMO thin films, in this research, we have tried to investigate physical properties of $\operatorname{In}_{2} \mathrm{O}_{3}: \mathrm{Mo}$ thin films.

\section{Experimental}

In this work, IMO thin films were prepared on glass substrates using spray pyrolysis technique. The chemical spray

\footnotetext{
*Author for correspondence (smrozati@guilan.ac.ir)
}

pyrolysis technique is one of the most commonly used techniques for preparation of transparent and conducting oxides owing to its simplicity, non-vacuum system of deposition and hence inexpensive method. The spray pyrolysis apparatus used in this work consists of a homemade spraying unit, substrate holder with heater and enclosure. The glass substrate is kept on a stainless steel (ss) plate. The heater is capable of heating the substrate up to a temperature of $700{ }^{\circ} \mathrm{C}$. $\mathrm{In}_{2} \mathrm{O}_{3}$ :Mo thin films were prepared by spraying a water solution containing indium chloride $\left(0.2 \mathrm{~g} \mathrm{InCl}_{3}\right)$ and $\mathrm{MoCl}_{5}$ used as dopant onto glass substrates heated at different substrate temperatures. Deposition of parameters include: distance between the spray nozzle and substrates is $25 \mathrm{~cm}$, the carrier gas using filtered compressed air, the spray rate is $19 \mathrm{~L} / \mathrm{min}$, volume of solution is $40 \mathrm{~mL}$. All the above mentioned parameters were kept constant and only the concentration of $\mathrm{MoCl}_{5}(0-20 \mathrm{wt} \%)$ and substrate temperature $\left(400-600^{\circ} \mathrm{C}\right)$ were changed.

X-ray diffraction (XRD) (Philips-PW-1830) was used to characterize the crystal structure and orientation of $\operatorname{In}_{2} \mathrm{O}_{3}: \mathrm{Mo}$ thin films. The power of the $\mathrm{XRD}(\mathrm{CuK} \alpha$ radiation, $\lambda=1.542 \AA$ ) was fixed at $30 \mathrm{kV}$ and $30 \mathrm{~mA}$ and the scanning angle, $2 \theta$, was varied in the range between $20^{\circ}$ and $80^{\circ}$ (step size $=0 \cdot 050$, time constant of recorder $=0.5 \mathrm{~s}$, threshold $=500$ ). Besides, to evaluate electrical and optical properties of films, Hall effect (PhysTech - RH2010) and a UVVIS spectroscopy (Cary 100 Scan Varian), respectively were carried out.

In this work, we first optimized the concentration of Mo wt\% using electrical resistivity and optical transparency and secondly, focused on the effect of substrate temperature on structural, electrical and optical properties of the samples with a constant molybdenum concentration of $1 \mathrm{wt} \%$. 
Table 1. Variation of electrical properties as a function of Mo-dopant concentration of IMO films deposited at $575{ }^{\circ} \mathrm{C}$.

\begin{tabular}{lcccccc}
\hline Mo $(\mathrm{wt} \%)$ & $R_{\mathrm{sh}}(\Omega / \square)$ & $\rho\left(\times 10^{-3} \Omega \mathrm{cm}\right)$ & $n\left(\times 10^{20} \mathrm{~cm}^{-3}\right)$ & $\left(\mathrm{cm}^{2} / \mathrm{V} \cdot \mathrm{s}\right)(\mu)$ & $\begin{array}{c}T \% \\
(\lambda=550 \mathrm{~nm})\end{array}$ & $\begin{array}{c}\text { FOM } \\
\left(\times 10^{-5}\right)\end{array}$ \\
\hline 0 & 5850 & 147 & $0 \cdot 06$ & $6 \cdot 71$ & 77 & $1 \cdot 25$ \\
$0 \cdot 5$ & 148 & $3 \cdot 95$ & $5 \cdot 78$ & $27 \cdot 4$ & $77 \cdot 3$ & $51 \cdot 5$ \\
1 & 129 & $3 \cdot 22$ & $5 \cdot 10$ & 38 & 78 & $64 \cdot 6$ \\
5 & 138 & $3 \cdot 70$ & $5 \cdot 26$ & $32 \cdot 1$ & $78 \cdot 5$ & $64 \cdot 4$ \\
15 & 152 & $3 \cdot 89$ & $5 \cdot 48$ & $29 \cdot 3$ & $76 \cdot 7$ & $46 \cdot 4$ \\
20 & 287 & $5 \cdot 28$ & $5 \cdot 31$ & $22 \cdot 3$ & 72 & $13 \cdot 04$ \\
\hline
\end{tabular}

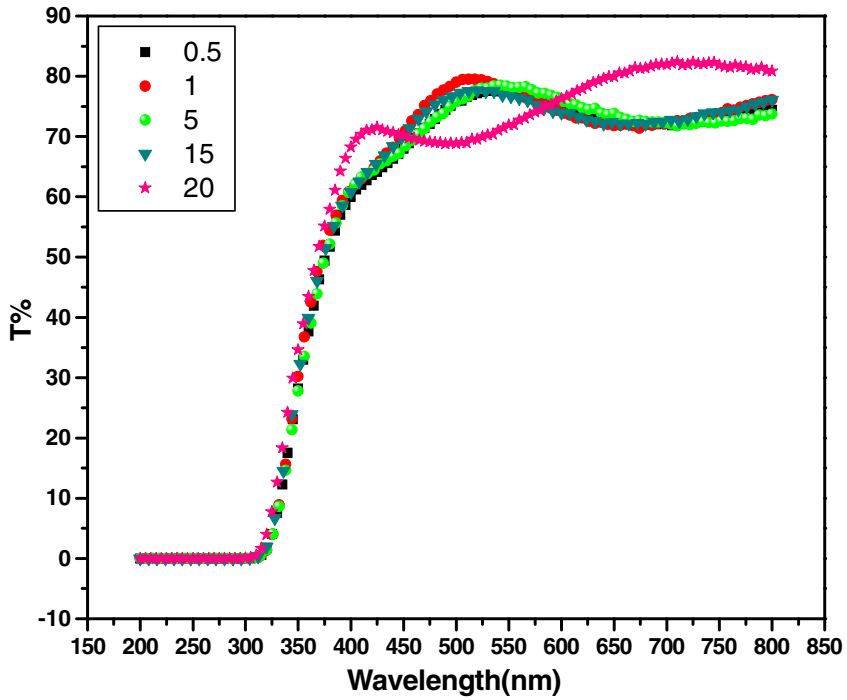

Figure 1. Transmittance spectra of IMO films prepared at $575^{\circ} \mathrm{C}$ as a function of Mo doping.

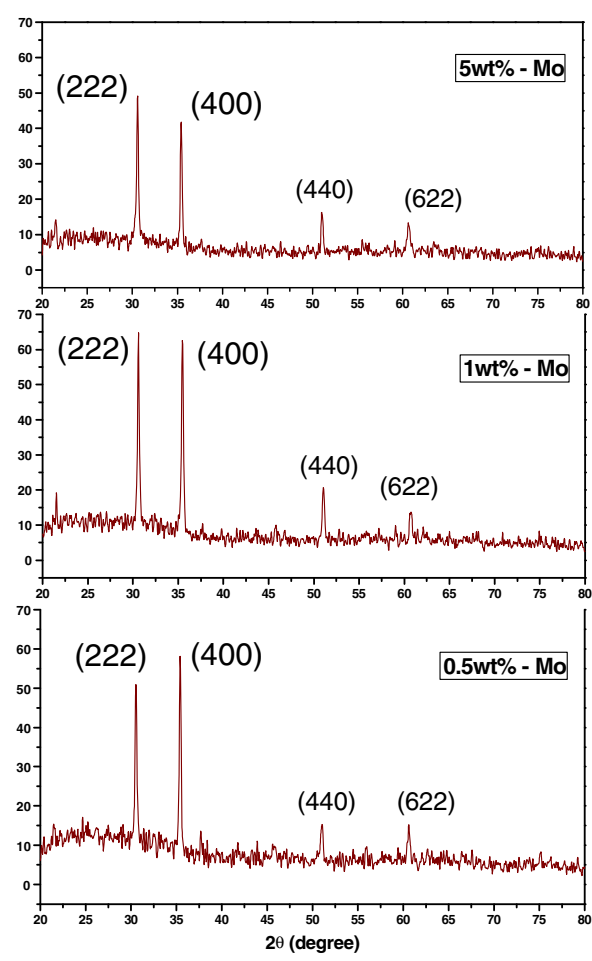

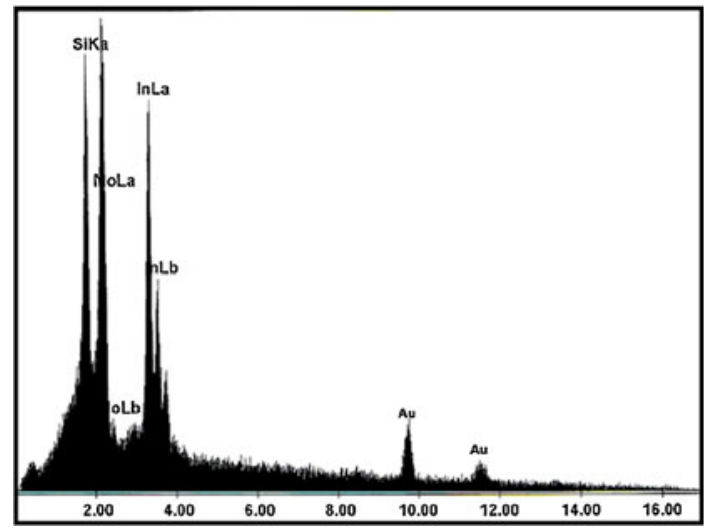

Figure 3. EDX spectra of IMO films prepared at $1 \mathrm{wt} \%$ of Mo concentration at $575^{\circ} \mathrm{C}$.

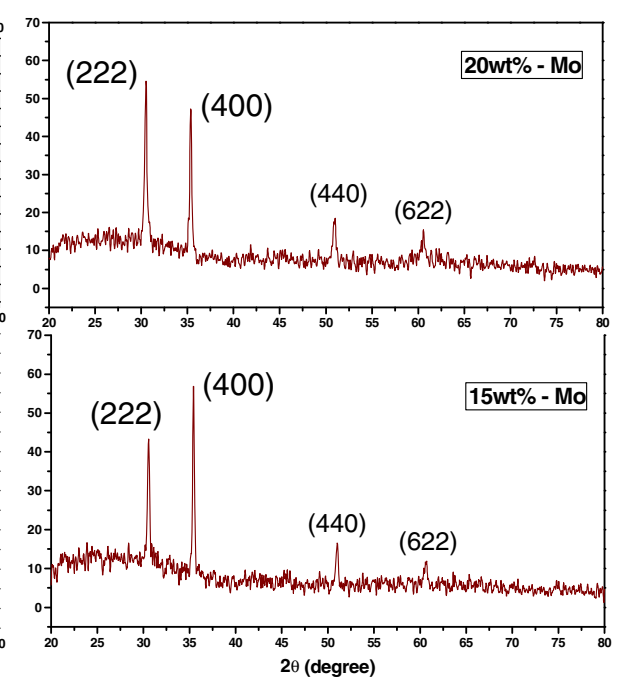

Figure 2. XRD pattern of IMO films obtained from various Mo dopings. 
Table 2. Variation of electrical properties of $1 \mathrm{wt} \% \mathrm{Mo}: \mathrm{In}_{2} \mathrm{O}_{3}$ thin films as a function of substrate temperature.

\begin{tabular}{lcccccc}
\hline$T_{\mathrm{s}}\left({ }^{\circ} \mathrm{C}\right)$ & $R_{\mathrm{sh}}(\Omega / \square)$ & $\rho\left(\times 10^{-3} \Omega \mathrm{cm}\right)$ & $n\left(\times 10^{19} \mathrm{~cm}^{-3}\right)$ & $\left(\mathrm{cm}^{2} / \mathrm{V} \cdot \mathrm{s}\right)(\mu)$ & $T \%$ & $\mathrm{FOM}\left(\times 10^{-5}\right)$ \\
\hline 400 & 3800 & 119 & 2.59 & 2.03 & $51 \cdot 6$ & 0.04 \\
450 & 597 & $17 \cdot 6$ & 4.15 & 8.56 & 57.6 & 0.67 \\
500 & 167 & $5 \cdot 11$ & 4.96 & 24.6 & 68.5 & 13.6 \\
550 & 94 & $2 \cdot 50$ & $6 \cdot 47$ & $38 \cdot 6$ & 77.8 & $86 \cdot 4$ \\
575 & 129 & $3 \cdot 22$ & $5 \cdot 10$ & 38 & 78 & 64.6 \\
600 & 152 & $2 \cdot 03$ & 7 & 43.9 & 85.8 & 142 \\
\hline
\end{tabular}

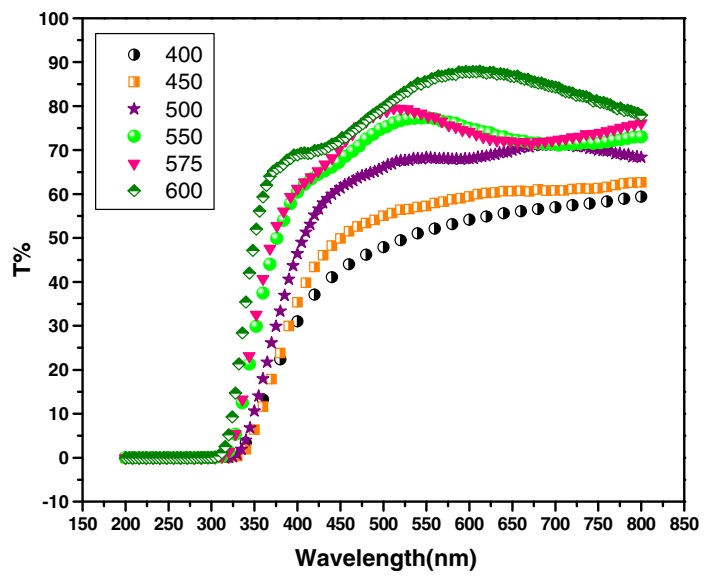

Figure 4. Optical transmission of IMO films prepared at $1 \mathrm{wt} \%$ Mo at various substrate temperatures.

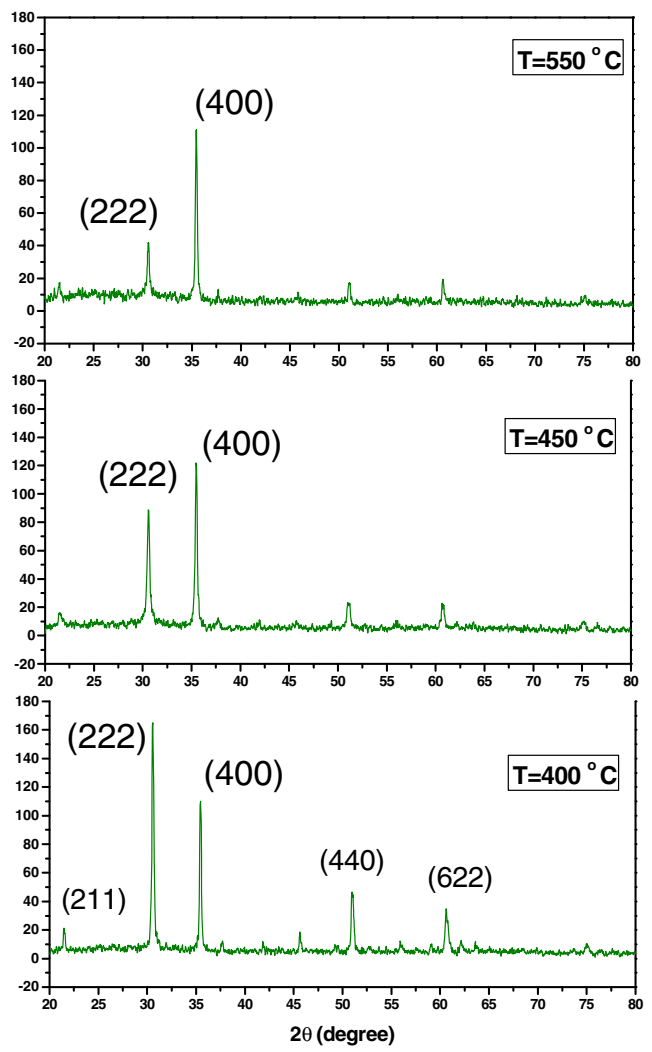

\section{Results and discussion}

The variation of electrical properties as a function of Mo doping concentrations is shown in table 1 . Electrical properties were determined at room temperature and Hall measurements in van der Pauw configuration. The negative sign of the Hall coefficient confirms $n$-type conductivity of $\mathrm{In}_{2} \mathrm{O}_{3}$ :Mo thin films. As shown in table 1, the Hall mobility $(\mu)$ and carrier concentration $(n)$ of IMO films were increased significantly with increasing only $0.5 \mathrm{wt} \%$ of Mo concentration. The sheet resistance decreased quickly and by increasing Mo concentration reached to a minimum value of $129 \Omega / \square$ for a Mo concentration of $1 \mathrm{wt} \%$. By further increase in Mo concentration (20 wt\%), the sheet resistance increased to a value of $287 \Omega / \square$. This evolution could be

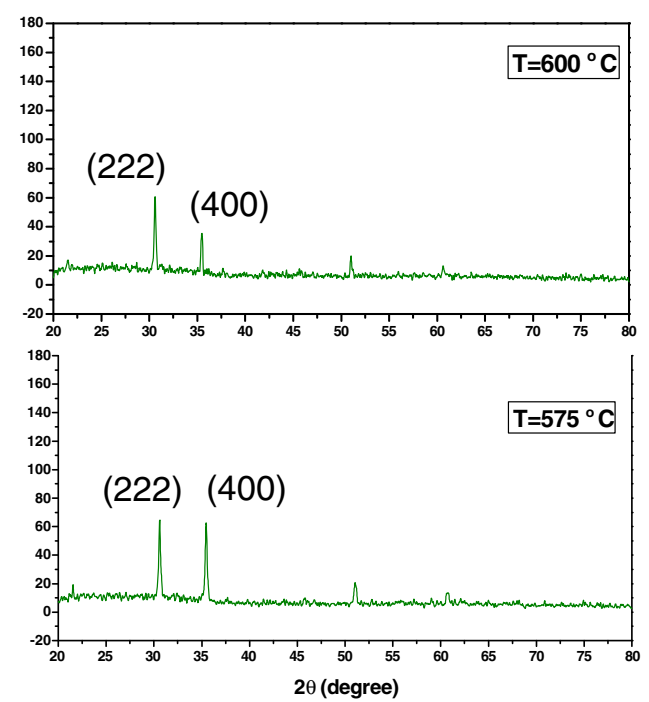

Figure 5. XRD patterns of $1 \mathrm{wt} \% \mathrm{Mo}: \mathrm{In}_{2} \mathrm{O}_{3}$ films prepared at various substrate temperatures. 
described in terms of solubility of Mo atoms in the $\operatorname{In}_{2} \mathrm{O}_{3}$ lattice. The maximum solubility of Mo-atoms in the $\mathrm{In}_{2} \mathrm{O}_{3}$ lattice is reached at approximately $1 \mathrm{wt} \%$. As the ionic radius of Mo is smaller than that of In, the excess Mo atoms may occupy interstitial positions and hence they deform the crystal structure which in turn reduces the mobility of carriers in these films (table 1). Thus the mobility, for doping levels of $1 \mathrm{wt} \%$, has a maximum and decreases continuously with further increase in the dopant.

Figure 1 shows variation of the optical transmission spectra as a function of Mo content of IMO films prepared at a substrate temperature of $575^{\circ} \mathrm{C}$. As shown in the figure, there is not much change in the optical transmission spectra of the prepared IMO films. Since we were looking for a layer with both high transparency and good resistivity, we had used figure of merit (FOM) (Haacke 1976). Thus, the optimized layer with $1 \mathrm{wt} \%$ of Mo concentration was selected according to most FOM.

Figure 2 shows XRD patterns as a function of Mo concentration for the IMO films prepared at a substrate temperature of $575{ }^{\circ} \mathrm{C}$. IMO thin films are polycrystalline and crystallize in a cubic structure of the bixbyite, since (222) and (400) oriented peaks, characteristic of a cubic structure, are present on the diffractograms. Note also that no characteristic peaks of impurity and dopant phases have been observed. Since the sheet resistance and transparency were not changed much with increasing Mo concentration, subsequently, XRD patterned are almost similar.

Figure 3 shows EDX spectra of IMO films that were prepared at a substrate temperature of $575{ }^{\circ} \mathrm{C}$ with a Mo content of $1 \mathrm{wt} \%$. The chemical compositions of Mo and In phases of the sample were identified. But in addition to Mo and In phases observed, other peaks (such as $\mathrm{Si}$ and $\mathrm{Au}$ ) that may be due to diffusion of alkali ions from the glass substrate to the films due to the high substrate temperature, are also observed.

According to the FOM (at $1 \mathrm{wt} \% \mathrm{Mo}$ ), we selected this optimal value for further investigation of the temperature effect on the growth mode. So, we fixed the doping concentration at $1 \mathrm{wt} \%$ Mo and studied the effect of substrate temperature.

Table 2 shows variation of electrical properties of IMO films as a function of substrate temperature. From table 2, one can note that the resistivity of the films was affected by the deposition temperature. The result shows that the sheet resistance decreased with increasing substrate temperature. This signifies that the dislocation and density of grain boundaries decreased. Therefore, the carrier concentration, mobility and conductivity quickly enhanced. Minimum resistivity, maximum mobility and carrier concentration were obtained for films deposited at $T_{\mathrm{s}}=600{ }^{\circ} \mathrm{C}$. But minimum sheet resistance $\left(R_{\mathrm{sh}}\right)$ was achieved at $550{ }^{\circ} \mathrm{C}$ and $R_{\mathrm{sh}}$ increased with increasing substrate temperature. This increase of $R_{\mathrm{sh}}$ may be due to diffusion of impurity of substrate from the substrate to the films at high substrate temperature.

Figure 4 shows curve of variation of the optical transmittance as a function of wavelength for the $1 \mathrm{wt} \% \mathrm{Mo}: \operatorname{In}_{2} \mathrm{O}_{3}$ films deposited at various substrate temperatures. The optical transmittance of the films increased from $51.6 \%$ to $85.8 \%$ with the increase of deposition temperature. The films deposited at $600{ }^{\circ} \mathrm{C}$ exhibited a high optical transmittance $(\approx 86 \%)$ in the visible region. The high transmittance observed in the films was attributed to less scattering effects, structural homogeneity and better crystallinity. There was a shift in the absorption edge to shorter wavelength for the optimum film, which was due to the Burstein-Moss shift (Burstein 1952).
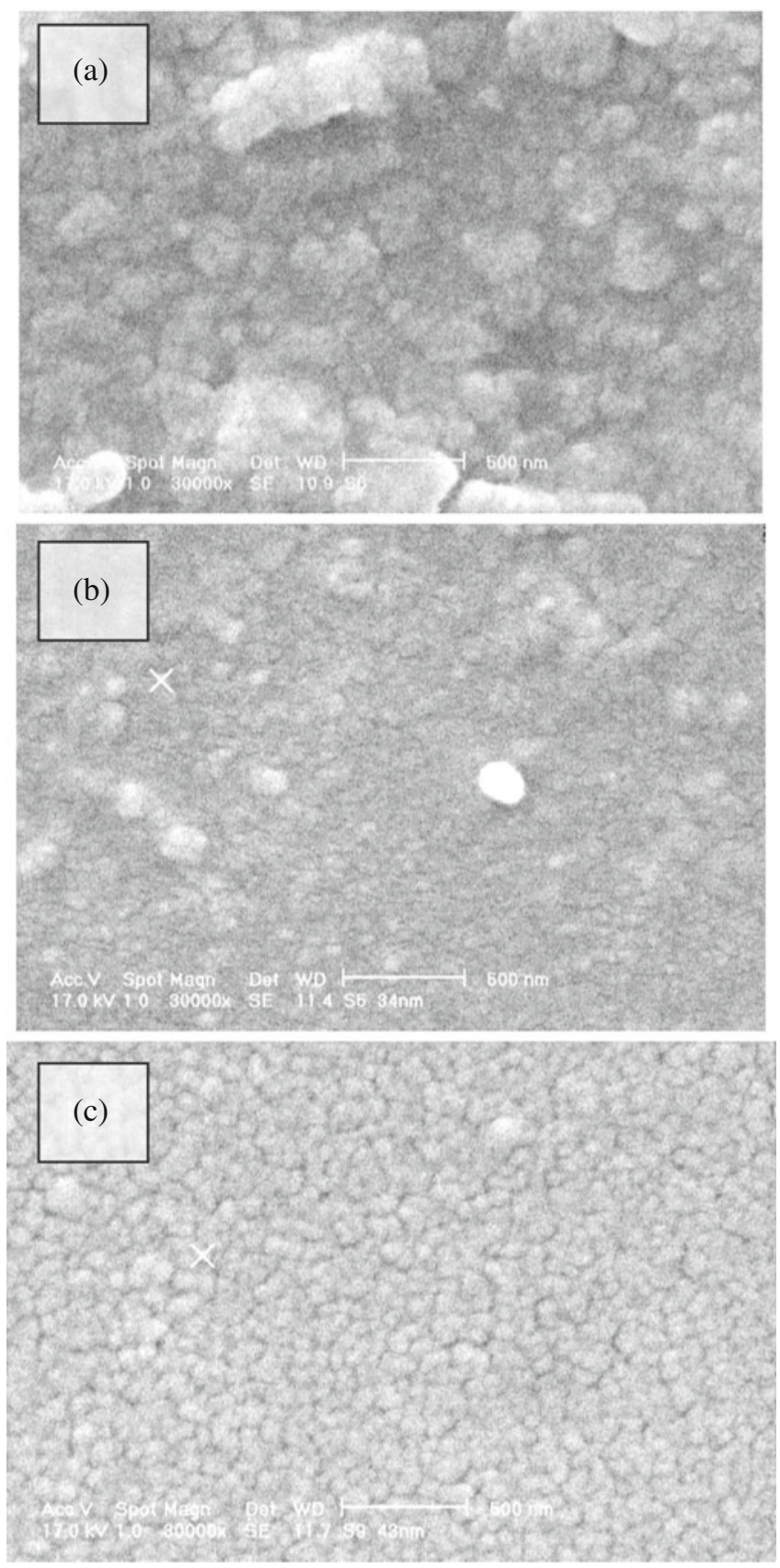

Figure 6. SEM images of $1 \mathrm{wt} \% \mathrm{Mo}: \mathrm{In}_{2} \mathrm{O}_{3}$ films prepared at different substrate temperatures: (a) $T_{\mathrm{s}}=550{ }^{\circ} \mathrm{C}$, (b) $T_{\mathrm{s}}=575{ }^{\circ} \mathrm{C}$ and (c) $T_{\mathrm{s}}=600{ }^{\circ} \mathrm{C}$. 
The variation of X-ray diffraction patterns of IMO films as a function of substrate temperature are shown in figure 5. IMO films are polycrystalline and crystallize in a cubic structure of the bixbite $\mathrm{Mn}_{2} \mathrm{O}_{3}$ (I) type. The preferred growth orientation of IMO thin films depends on the substrate temperature. The intensity of the (400) to (222) reflection is used to evaluate the temperature effect on the film texture. The ratio $I_{400} / I_{222}$ increased with increasing substrate temperature, at $550{ }^{\circ} \mathrm{C}$ leading to a clear predominance of the (400) peak. Other peaks [(211), (440), (622)] are also observed, but their intensity is very small compared to that of the (222) and (400) peaks. Nevertheless, their presence decreased with increasing substrate temperature. As a result, optical transmittance increased with disappearance of these peaks.

Figure 6 shows SEM images of 1 wt $\%$ Mo: $\operatorname{In}_{2} \mathrm{O}_{3}$ films prepared at different substrate temperatures. These results clearly show that there are changes in the surface morphology of IMO films due to a change in substrate temperature. The size of crystals is in the range of nanometer. The size of particles changes with substrate temperature. The films exhibit a good surface morphology and are entirely covered by grains with increasing substrate temperature.
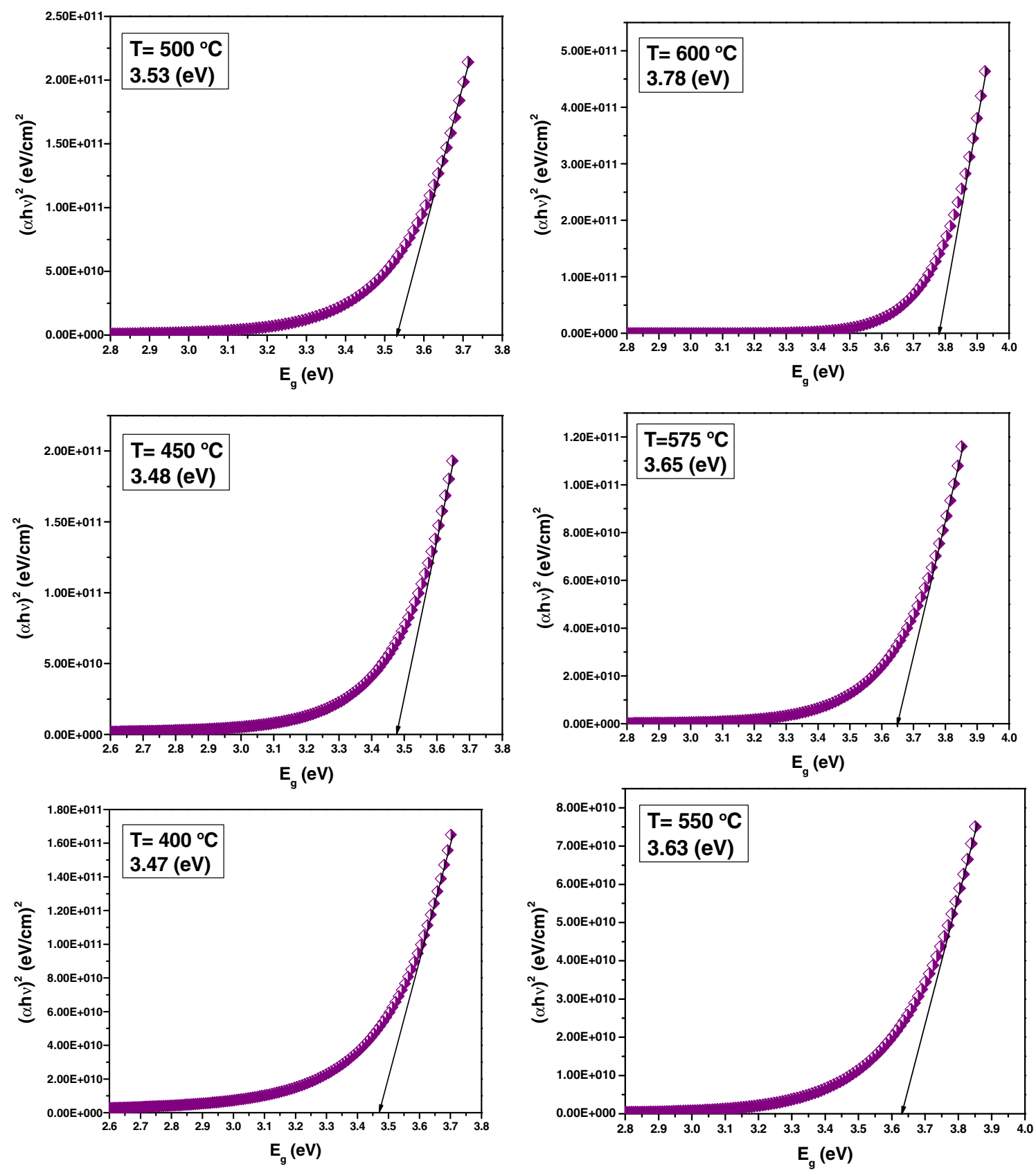

Figure 7. Variation of optical bandgap in IMO films with various substrate temperatures. 
The optical absorption in the UV region is dominated by the optical bandgap of the semiconductors. The optical bandgap $\left(E_{\mathrm{g}}\right)$ of the semiconductors is related to the optical absorption coefficient $(\alpha)$ and the incident photon energy $(h v)$ by (1) (Granqvist 2000),

$$
\alpha h v=\left(E_{\mathrm{g}}-h v\right)^{n},
$$

where $n$ depends on the kind of optical transition that prevails. Specifically, $n$ is $1 / 2,3 / 2,2$ and 3 when the transition is directly allowed, directly forbidden, indirectly allowed and indirectly forbidden, respectively. The variation of the optical bandgap of 1 wt $\%$ Mo: $\operatorname{In}_{2} \mathrm{O}_{3}$ films with various substrate temperatures is shown in figure 7 . The shift of the absorption edge towards the shorter wavelength (figure 4), resulting from the energy bandgap of IMO films changes from 3.47 to $3.78 \mathrm{eV}$ with increasing substrate temperature.

\section{Conclusions}

In this research, molybdenum-doped indium oxide (IMO) nanostructures were prepared at different Mo concentrations and substrate temperatures using spray pyrolysis technique. Then, the effects of above parameters on structural, electrical and optical properties of nanostructured thin films of IMO have been reported in this article. The optimum IMO films were prepared using $0.2 \mathrm{~g} \mathrm{InCl}_{3}$ with Mo concentration of $1 \mathrm{wt} \%$ at a substrate temperature of $550{ }^{\circ} \mathrm{C}$. With this condition the minimum sheet resistance was about $94 \Omega / \square$ and the optical transmission in visible region was $77.8 \%$.

\section{References}

Anna Selvan J A, Delahoy A E, Guo S and Li Y 2006 Sol. Energ. Mater. Solar C. 903371

Boycheva S, Sytchkova A K, Grilli M L and Piegari A 2007 Thin Solid Films $\mathbf{5 1 5} 8469$

Brown J R, Haycock P W, Smith L M, Jones A C and Williams E W 2000 Sensor Actuator B63 109

Burstein E 1952 Phys. Rev. 93632

Chen H, Qiu C, Wong M and Kwak H S 2003 IEEE Electron Device Lett. 24315

El Hichou A, Kachouance A, Bubendorff J L, Addou M, Ebothe J, Troyon M and Bougrine A 2004 Thin Solid Films 458263

Golshahi S, Rozati S M, Martins R and Fortunato E 2009 Thin Solid Films $\mathbf{5 1 8} 1149$

Granqvist C G 2000 Sol. Energ. Mater. Sol. C. 60201

Haacke G 1976 J. Appl. Phys. 474086

Kim J H, Jeon K A, Kim G H and Lee S Y 2006 Appl. Surf. Sci. 252 4834

Korotcenkov G, Brinzari V and Cerneavschi A 2004 Sensor Actuator $\mathbf{B 9 8} 122$

Korotcenkov G, Cornet A, Rossinyol E, Arbiol J, Brinzari V and Blinov Y 2005 Thin Solid Films 310471

Lessman R and Hummelgen I A 2004 Mater. Res. 7447

Macedo A G, de Vascooncelos E A, Valaski R, Muchenski F, da Silva Jr E F, da Silva A F and Roman L S 2008 Thin Solid Films $\mathbf{5 1 7} 870$

Rozati S M and Akesteh Sh 2007 Mater. Character. 58319

Rozati S M and Akesteh Sh 2008 Cryst. Res. Technol. 43273

Rozati S M, Moradi S, Golshahi S, Martins R and Fortunato E 2009 Thin Solid Films 5181279

Ryu H, Kang J, Han Y, Kim D, Park J J, Park W K and Yang M S 2003 J. Electron. Mater. 23919

Tahar R B H, Ban T, Ohya Y and Takahashi Y 1997 J. Appl. Phys. 82865 